\title{
Swimming-induced pulmonary edema
}

\author{
Pablo Paz, MD (D), John Makram, MD (D), Haneen Mallah, MD, Barbara Mantilla, MD, Somedeb Ball, MD, and \\ Kenneth Nugent, MD \\ Department of Internal Medicine, Texas Tech University Health Sciences Center, Lubbock, Texas
}

\begin{abstract}
Swimming-induced pulmonary edema occurs when fluid accumulates in the lungs in the absence of water aspiration during swimming and produces acute shortness of breath and a cough with blood-tinged sputum. We report a case of a 58-year-old female athlete presenting with acute dyspnea during the swimming portion of a half-triathlon competition. She had complete resolution within $24 \mathrm{~h}$ of presentation.
\end{abstract}

KEYWORDS Athlete; cold water; immersion pulmonary edema; swimming; triathlon

wimming-induced pulmonary edema (SIPE) is a type of pulmonary edema that occurs during surface or underwater swimming and causes the accumulation of fluid in the lungs without water aspiration and consequently symptoms of pulmonary edema. ${ }^{1,2}$ It has an estimated prevalence of $1.4 \%$ among triathletes. ${ }^{1}$ We report a patient with acute dyspnea during the swimming portion of a half-triathlon competition.

\section{CASE DESCRIPTION}

A 58-year-old white woman presented with sudden dyspnea associated with cough productive of frothy pink sputum that began while swimming during a half-triathlon competition. After being pulled out of the water, she received bronchodilator treatments without improvement. She denied water aspiration. Her blood pressure was $133 / 87 \mathrm{~mm} \mathrm{Hg}$; heart rate, 102 beats per minute; respiratory rate, 24 breaths per minute; temperature, $97^{\circ} \mathrm{F}$; and oxygen saturation, $83 \%$ on room air. She was in moderate respiratory distress but had no laryngospasm. She had scant bibasilar crackles and no lower limb edema. The chest radiograph showed bilateral alveolar infiltrates consistent with pulmonary edema (Figure 1a). Her cardiac enzymes were normal, and the brain natriuretic peptide level was $126 \mathrm{pg} / \mathrm{mL}$ (normal $<124 \mathrm{pg} / \mathrm{mL}$ ). A transthoracic echocardiogram showed normal systolic and diastolic function with trace mitral and tricuspid regurgitation.
She required respiratory support with bilevel positive airway pressure ventilation and was given $40 \mathrm{mg}$ of furosemide. After $4 \mathrm{~h}$, her oxygen saturation improved, and she was switched to nasal cannula for oxygenation. After $24 \mathrm{~h}$, a second chest radiograph revealed clear lung fields (Figure 1b), she no longer required oxygen, and her symptoms had resolved.

\section{DISCUSSION}

SIPE is an unusual complication that can occur during heavy exercise in water. It is often misdiagnosed and can rapidly deteriorate into life-threatening situations. ${ }^{3}$ Moon et al identified 58 deaths between October 2008 and November 2015 in the United States and Canada in triathletes during training or competition; 42 deaths occurred during swimming. ${ }^{2}$ Wilmshurst et al suggested that swimming in cold water and hypertension are the most important factors that predispose athletes to develop SIPE. ${ }^{4}$ Other important factors during the event include ambient air temperature, exertion level, and anxiety. ${ }^{4,5}$ Potential risk factors include older age, female sex, left ventricular hypertrophy, and obesity. ${ }^{6}$ Postmortem studies have reported increased heart mass ( 9 of 20 available autopsies) and left ventricular free wall thickness (6 of 14 autopsies) in some triathletes. ${ }^{2}$

In 2006, Ludwig et al suggested the following criteria for SIPE: (1) acute onset of dyspnea or hemoptysis during or immediately after swimming; (2) no history of water aspiration, laryngospasm, or preceding infectious process; (3) hypoxemia, defined by an oxygen saturation $<92 \%$ by pulse

Corresponding author: Pablo Paz, MD, Department of Internal Medicine, Texas Tech University Health Sciences Center, 3601 4th Street, Lubbock, TX 79430 (e-mail-pablo.paz@ttuhsc.edu)

Received December 15, 2019; Revised February 18, 2020; Accepted February 24, 2020. 
Table 1. Characteristics of patients with swimming-induced pulmonary edema in published reports

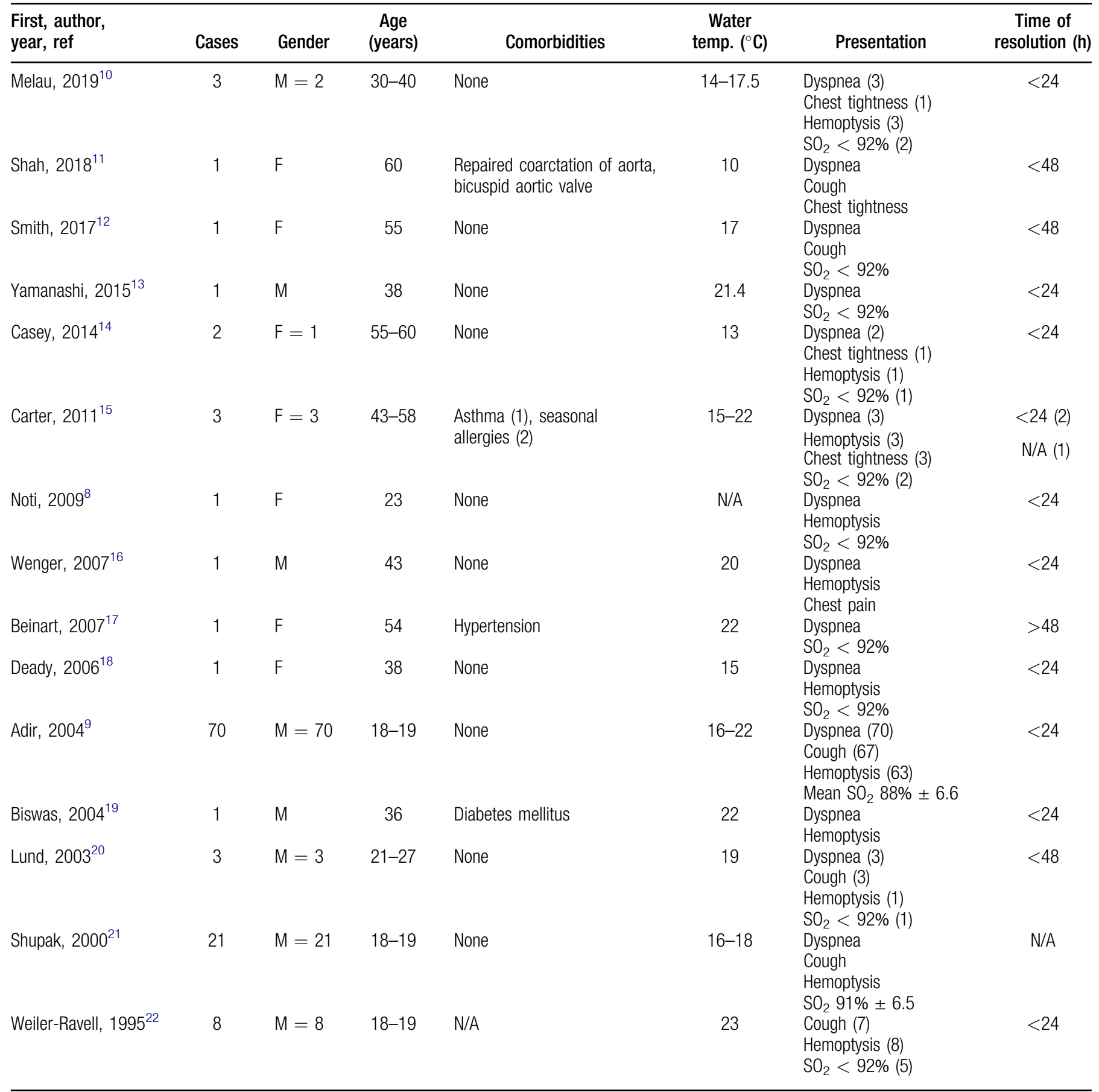

$\mathrm{N} / \mathrm{A}$ indicates not available; $\mathrm{SO}_{2}$, oxygen saturation.

oximetry or an alveolar-arterial gradient $>30 \mathrm{~mm} \mathrm{Hg}$; and (4) radiographic opacities consistent with an alveolar filling process and/or interstitial pulmonary edema that resolve within $48 \mathrm{~h}^{7}$ Other potential cardiac causes of pulmonary edema need to be excluded. ${ }^{8}$ Our patient presented with a history and radiographic findings highly suggestive of SIPE; her clinical and radiological improvement within $24 \mathrm{~h}$ confirmed the diagnosis. On the day our patient swam, the water temperature was $21^{\circ} \mathrm{C}$ and the air temperature was $24^{\circ} \mathrm{C}$. She did not have a history of hypertension.
Adir et al studied 70 naval trainees who developed SIPE during swimming time trials over 2.4 to $3.6 \mathrm{~km}$ in open seas. ' These trials took between 30 and 45 min with mean water temperatures during training of $19.6^{\circ} \mathrm{C}$. All trainees developed dyspnea, 67 developed cough, and 39 had hemoptysis. On physical examination, 64 trainees had crackles, and 6 had wheezes. The mean oxygen saturation after exercise was $88.4 \%$. Chest radiographs taken 12 to $18 \mathrm{~h}$ after presentation were within normal limits. Sixteen trainees had recurrent episodes of SIPE. Table 1 summarizes other case reports and studies. ${ }^{8-22}$ 

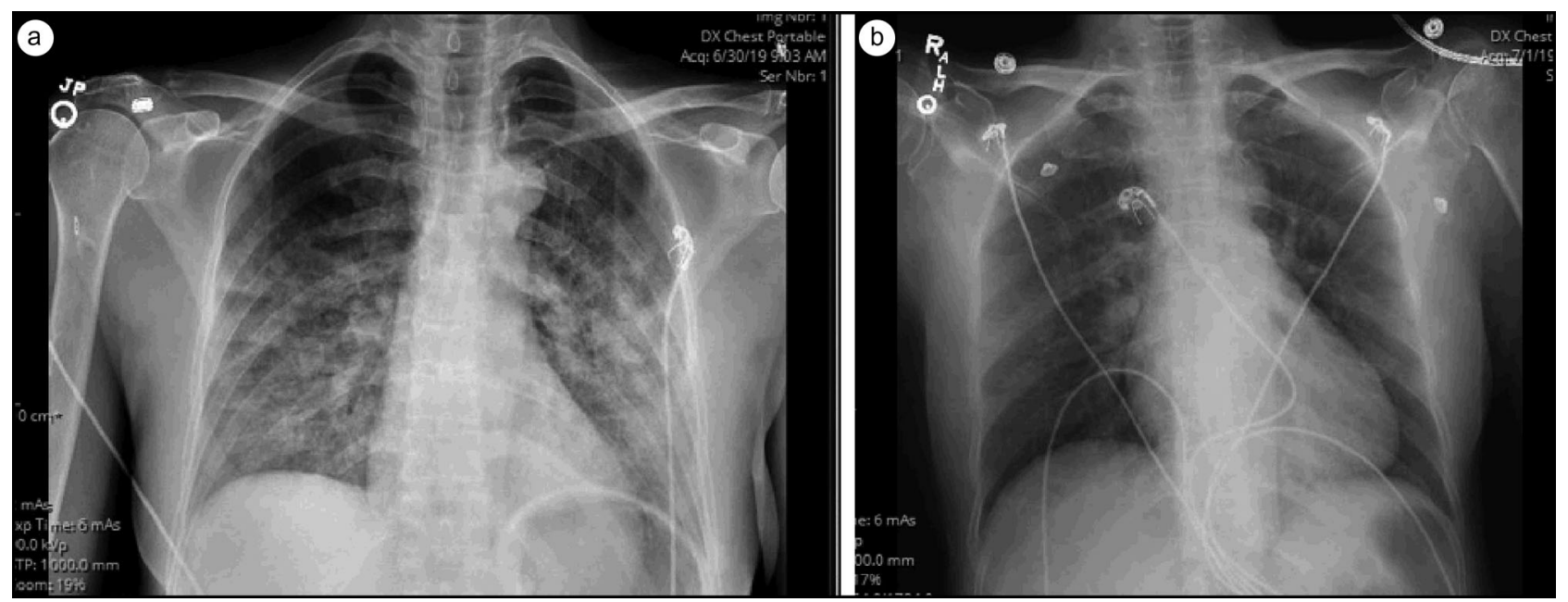

Figure 1. Chest radiographs (a) on admission, showing bilateral alveolar infiltrates suggestive of pulmonary edema and (b) after treatment, showing reduction in alveolar infiltrates.

The pathophysiological events during SIPE remain incompletely understood. There is a moderate association between water temperature and the incidence of SIPE, ${ }^{23}$ and the temperatures associated with SIPE have ranged from $13^{\circ} \mathrm{C}$ to $23^{\circ} \mathrm{C}^{8}$ Subjects with a history of SIPE have significantly elevated mean pulmonary artery pressures (34.0 vs $22.5 \mathrm{~mm} \mathrm{Hg}$ ) and pulmonary artery wedge pressures (18.8 vs $11.0 \mathrm{~mm} \mathrm{Hg}$ ) compared to controls during exercise in $20^{\circ} \mathrm{C}$ water. ${ }^{24}$ Immersion in cold temperatures causes redistribution of blood from the extremities to the thorax due to vasoconstriction, with increased blood volume in central vessels and increased pulmonary artery pressures. ${ }^{20}$ In addition, the increase in the pulmonary artery wedge pressure suggests decreased left ventricular diastolic compliance, which increases pressures in pulmonary capillaries. The increased pulmonary blood flow associated with exercise and increased hydrostatic pressure in capillaries could increase vascular permeability. Ludwig et al studied five combat swimmers who developed acute respiratory symptoms following swimming 300 to $1600 \mathrm{~m}$ in open water with water temperatures ranging from $14^{\circ} \mathrm{C}$ to $18^{\circ} \mathrm{C}^{25}$ All subjects had airspace consolidation on chest radiographs. These subjects underwent bronchoscopy and had bronchoalveolar lavage fluid containing increased numbers of erythrocytes and increased albumin and immunoglobulin G levels, which cleared on subsequent bronchoscopies after symptom resolution. These results suggest that stress failure occurs in pulmonary capillaries secondary to increased pressures in patients with SIPE. In summary, SIPE should be considered in patients with acute respiratory symptoms during and after swimming events.

\section{ORCID}

Pablo Paz (iD) http://orcid.org/0000-0001-9065-6350

John Makram iD http://orcid.org/0000-0003-3868-0120
1. Miller IL. Fearless Swimming for Triathletes: Improve Your Open Water Skills. Maidenhead, England: Meyer \& Meyer Sport; 2011.

2. Moon RE, Martina SD, Peacher DF, Kraus WE. Deaths in triathletes: immersion pulmonary oedema as a possible cause. BMJ Open Sport Exerc Med. 2016;2(1):e000146. doi:10.1136/bmjsem-2016-000146.

3. Grunig H, Nikolaidis PT, Moon RE, Knechtle B. Diagnosis of swimming induced pulmonary edema—a review. Front Physiol. 2017;8: 652. doi:10.3389/fphys.2017.00652.

4. Wilmshurst PT, Nuri M, Crowther A, Webb-Peploe MM. Coldinduced pulmonary oedema in scuba divers and swimmers and subsequent development of hypertension. Lancet. 1989;1(8629):62-65. doi: 10.1016/S0140-6736(89)91426-8.

5. Alonso JV, Chowdhury M, Borakati R, Gankande U. Swimminginduced pulmonary oedema an uncommon condition diagnosed with POCUS ultrasound. Am J Emerg Med. 2017;35(12):1986.e1983-1986. e1984.

6. Gempp E, Demaistre S, Louge P. Hypertension is predictive of recurrent immersion pulmonary edema in scuba divers. Int J Cardiol. 2014; 172(2):528-529. doi:10.1016/j.ijcard.2014.01.021.

7. Ludwig BB, Mahon RT, Schwartzman EL. Cardiopulmonary function after recovery from swimming-induced pulmonary edema. Clin J Sport Med. 2006;16(4):348-351. doi:10.1097/00042752-200607000-00011.

8. Noti F, Helbling A, Allemann Y. Swimming-induced pulmonary oedema. Forum Med Suisse. 2009;9(08):174-176. doi:10.4414/fms. 2009.06756.

9. Adir Y, Shupak A, Gil A, et al. Swimming-induced pulmonary edema: clinical presentation and serial lung function. Chest. 2004;126(2): 394-399. doi:10.1378/chest.126.2.394.

10. Melau J, Bonnevie-Svendsen M, Mathiassen M, Mykland Hilde J, Oma L, Hisdal J. Late-presenting swimming-induced pulmonary edema: a case report series from the Norseman Xtreme Triathlon. Sports (Basel). 2019;7(6):137. doi:10.3390/sports7060137.

11. Shah AB, Baggish AL. Swimming-Induced Pulmonary Edema [Latest in Cardiology Expert Analysis]. Washington, DC: American College of Cardiology; 2018. https://www.acc.org/latest-in-cardiology/articles/ 2018/08/14/06/49/swimming-induced-pulmonary-edema.

12. Smith R, Brooke D, Kipps C, Skaria B, Subramaniam V. A case of recurrent swimming-induced pulmonary edema in a triathlete: the need for awareness. Scand J Med Sci Sports. 2017;27(10):1130-1135. doi:10.1111/sms.12736. 
13. Yamanashi H, Koyamatsu J, Nobuyoshi M, Murase K, Maeda T. Exercise-induced pulmonary edema in a triathlon. Case Rep Med. 2015;2015:1-4. doi:10.1155/2015/968152.

14. Casey H, Dastidar AG, MacIver D. Swimming-induced pulmonary oedema in two triathletes: a novel pathophysiological explanation. $J R$ Soc Med. 2014;107(11):450-452. doi:10.1177/0141076814543214.

15. Carter EA, Koehle MS. Immersion pulmonary edema in female triathletes. Pulm Med. 2011;2011:1-4. doi:10.1155/2011/261404.

16. Wenger M, Russi EW. Aqua jogging-induced pulmonary oedema. Eur Respir J. 2007;30(6):1231-1232. doi:10.1183/09031936.00116407.

17. Beinart R, Matetzky S, Arad T, Hod H. Cold water-induced pulmonary edema. Am J Med. 2007;120(9):e3. doi:10.1016/j.amjmed.2006.08.030.

18. Deady B, Glezo J, Blackie S. A swimmer's wheeze. CJEM. 2006;8(4): 281, 297-288. doi:10.1017/s1481803500013853.

19. Biswas R, Shibu PK, James CM. Pulmonary oedema precipitated by cold water swimming. Br J Sports Med. 2004;38(6):e36-e36. doi:10. 1136/bjsm.2004.012138.

20. Lund KL, Mahon RT, Tanen DA, Bakhda S. Swimming-induced pulmonary edema. Ann Emerg Med. 2003;41(2):251-256. doi:10.1067/ mem.2003.69.
21. Shupak A, Weiler-Ravell D, Adir Y, Daskalovic YI, Ramon Y, Kerem D. Pulmonary oedema induced by strenuous swimming: a field study. Respir Physiol. 2000;121(1):25-31. doi:10.1016/S0034-5687(00) 00109-2.

22. Weiler-Ravell D, Shupak A, Goldenberg I, et al. Pulmonary oedema and haemoptysis induced by strenuous swimming. BMJ. 1995; 311(7001):361-362. doi:10.1136/bmj.311.7001.361.

23. Hohmann E, Glatt V, Tetsworth K. Swimming induced pulmonary oedema in athletes-a systematic review and best evidence synthesis. BMC Sports Sci Med Rehabil. 2018;10(1):18. doi:10.1186/s13102018-0107-3.

24. Moon RE, Martina SD, Peacher DF, et al. Swimming-induced pulmonary edema: pathophysiology and risk reduction with sildenafil. Circulation. 2016;133(10):988-996. doi:10.1161/CIRCULATIONAHA.115.019464.

25. Ludwig BB, Mahon RT, Parrish JS, Lamb C, Kerr S. Pulmonary edema and combat swimmers: clinical and bronchoalveolar lavage description demonstrating stress failure of the pulmonary capillaries [abstract]. Undersea Hyp Med. 2004. http://archive.rubicon-foundation.org/1490. 